\title{
Tourism impact on coastal environment
}

\author{
S. Zahedi \\ Allameh Tabataba'i University, Iran
}

\begin{abstract}
Tourism development in the coastal environment has interfaced with the original characteristics of the area upon which it relied for attracting tourists. An overall review of tourism research on the environment shows that nations do not give priority to environmental sustainability and disregard it to the benefit of economic development. Rapid and uncontrolled tourism development in the coastal zones has exposed their fragile ecosystems to an ever-increasing risk of environmental degradation. Tourism has also impacted on global warming through excessive energy use, transportation, water consumption, waste generation, etc. The impacts of tourism have been sorted into four general categories, with more elaboration on the impacts of ' $3 \mathrm{Ss}$ ' tourism on coastal areas, followed by a few facts about the negative impacts of tourism in different countries; the author presents a general framework for tourism impact assessment in coastal environments. The article ends with some suggestions in the hope of effective transition towards sustainable tourism in coastal areas.
\end{abstract}

Keywords: complex systems, 3 Ss tourism, green productivity index, TIACA.

\section{Introduction}

Tourism is the interrelated system that includes tourists and the associated services that are provided and utilized (facilities, attractions, transportation and accommodation) to aid in their movement $[14$, p. 2]. The prerequisites for tourism are: attractiveness, facilities, accessibility of destination, ability to travel, and motivation $[19,27]$.

Tourism in coastal areas is one of the fastest growing types of the world tourism industry, but whether it destroys more than it protects will depend upon how it is put into practice. Tourism development in the coastal environment has interfaced with the attractiveness of the destinations and has changed the original characteristics of the area upon which it relied for attracting tourists. This means 
that tourism in coastal regions, although it is ecologically based, it is not ecologically sound. An overall review of tourism research on environment shows that nations do not give priority to environmental sustainability and disregard environmental protection to the benefit of economic development. As a matter of fact, all three sectors of the society: government, private and social sectors, are working to the detriment of the environment. According to Higham, the tourism industry has done little more than pay lip service to the objective of sustainable development, notwithstanding the rhetoric of sustainable development; economic viability is the bottom line of sustainable tourism operations [18, p. 7].

\section{Tourism research on environment}

Tourism research on ecological impacts started during the 1960s and 1970s. Concerns over environmental issues in the realm of tourism studies, according to Fennell, gained a tremendous boost in the mid 1970s from the efforts of Budowski [2], Krippendorf [25] and Cohen [6] in their work on tourism and the environment. Budowski identified three different 'states' in tourism's relationship with environmental conservation: conflict, coexistence and symbiosis. He felt that the relationship at the time was one of coexistence moving towards conflict. Krippendorf was one of the first to write on the importance of planning, and the dispersion of tourists and tourism developments, as a means by which to minimize impacts [14, p. 63]. Cohen discussed the distinct differences between development for purposes of improvement and aesthetic appeal versus the vulgar, undesirable, and irreparable damage created by modern tourism [14]. Tourism research on ecological impacts continued throughout 1980s and since then concern over environmental impacts of tourism has increased. Many researchers emphasized on evaluating the impacts of tourism on environment among which, Pearce [33], offered a framework for the study of tourism and environmental stress. In his framework, he included stressor activities, the pressure resulting from the activity, the primary environmental response, and the secondary human response or reaction of the stress [33]. Others have identified a whole range of different tourism impacts on environment, their sources, and regions in which these take place. The authors note that sources of impacts cited in the literature include trampling (vegetation, microbes, soils) access roads and trails, built facilities and camp grounds (camp sites and firewood), water edges (river banks, lakes and reservoirs, coastal areas and coral reefs). Although up until now, a considerable amount of research has been emphasized on the impacts of tourism on the environment, the author believes that gathering exact data on environmental impacts of tourism is rather difficult because the actual impacts of tourism on the environment will only become apparent over a longer period of time. Of course, this limitation should not be used as an excuse to avoid evaluation of tourism activities on the environment. In order to overcome this limitation, academics, with the cooperation of practitioners, should conduct new research on this issue by employing a multi-disciplinary approach to conceive environmental impacts from different angles, with a system perspective. 


\section{Tourism excessive development}

Rapid and uncontrolled tourism development in coastal areas has exposed their fragile ecosystems to an ever-increasing risk of environmental degradation. Ecosystems are the complex interconnections of plants, animals, and physical and chemical factors that make up the natural environments [24, p. 195]. Overcrowding, poor sewage disposal, boat-generated waste, beach erosion, overfishing, and destruction of wildlife habitats have been reported as some of the negative consequences of excessive tourism development in the coastal areas.

These detrimental activities will have impacts on the attractiveness of the raw materials of tourism in these areas. They would also degrade the sensitive ecosystem and threaten the environmental quality of the area for the next generations. Tourism has also impacted on global warming through excessive energy use, transportation, water consumption, solid and liquid waste generation etc. There is a link between temperature and the related phenomena of cloud cover, wind patterns and velocity, rainfall and snow cover and these in turn relate to both terrestrial and marine environments [8, p. 353].

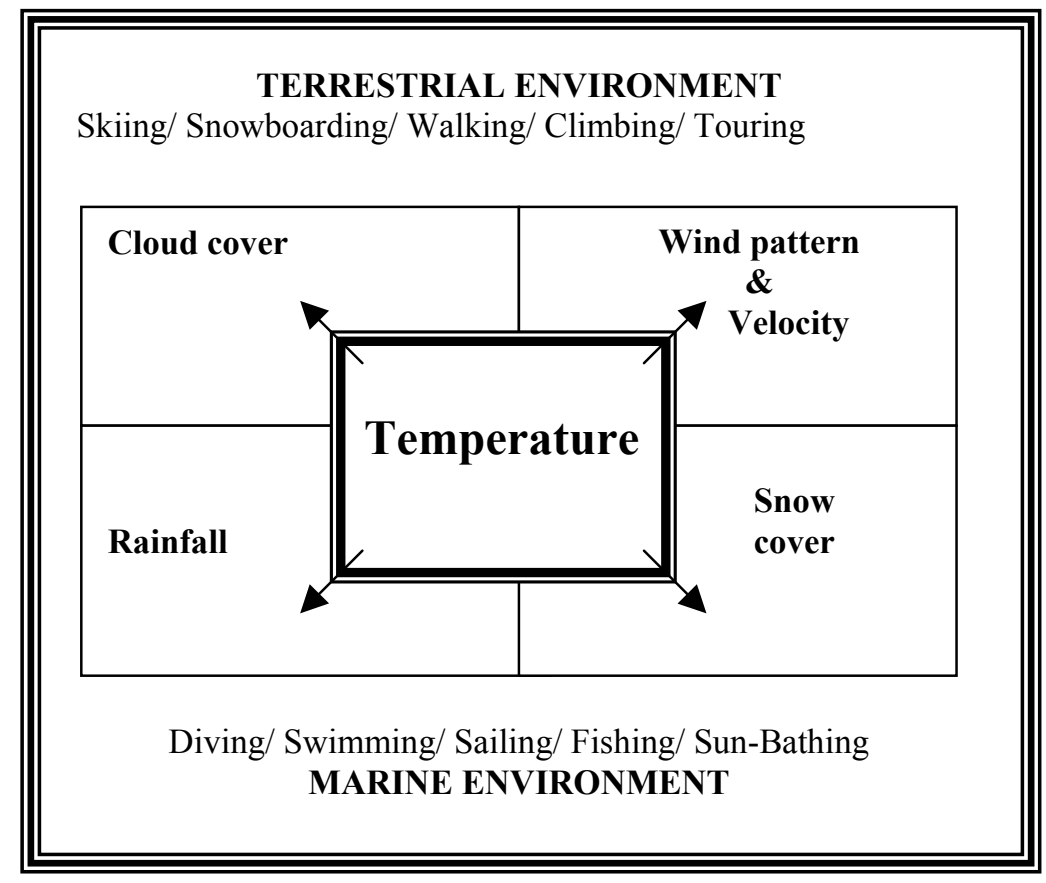

Figure 1: Climate change and tourism.

The results of climate research show that man has intensified the greenhouse effect by increasing the concentration of carbon dioxide in the earth's atmosphere which is accompanied by a rise in global average temperature, the rise of sea level and changes in vegetation [27, p. 285]. This geological change will have an 
impact on the attractiveness of the environment and may decrease the tourism demand in the area. If we are to manage tourism development in a sustainable way we need to have a better understanding of its positive and negative impacts on destinations.

\section{Tourism impacts}

The impacts of tourism can be sorted into four general categories: economic, political, social and cultural, and environmental impacts. Each category includes positive and negative impacts. In order to move towards sustainability, community and tourism leaders must try to maximize the positive impacts and to minimize the negative impacts of tourism in the host community. The following are some of the tourism impacts which are most cited in the literature $[3,4,9,17$, $20,22]$.

\subsection{Economic impacts}

Some of the positive economic impacts of tourism are: increasing employment opportunities, generating income, spending more on infrastructure and public utilities, raising the standards of living and improving the local economy. Among the negative impacts are: inflationary impacts of tourism expenditures, increase in the price of goods and services, land and housing, and cost of living, increase in health-care, police and fire protection, increase potential for imported labor, increase cost for additional infrastructure ( water, sewer, power, fuel,...).

\subsection{Political impacts}

Tourism development has some positive political impacts such as reducing political unrest due to unemployment, increasing the level of security in the community, raising mutual esteem and understanding among different nations. Some of the negative political impacts of tourism are: using tourism as a means towards political purposes, kidnapping tourists, increasing the possibility of political riots among oppositions to government.

\subsection{Social and cultural impacts}

Tourism provides opportunities for meeting different people, exchanging ideas and promoting cultural values and beliefs. This might promote mutual recognition among nations and increase tolerance of cultural differences. Tourism can increase availability of recreation facilities, increase welfare and the quality of local people's life and promote a higher level of psychological satisfaction through interaction with other travelers [4, p. 9]. Tourism might also have negative impacts: language and cultural effects, unwanted lifestyle changes, demonstration effects, introducing bad habits to the local population, health problems (AIDS and Hepatitis), increase in crime, traffic congestion and crowding which produces stress, annoyance, conflict and anger. It may also cause displacement of residents for expansion of tourism facilities. Tourism 
development may cause neglect of other sectors and non-tourist activities and it may increase pressure on infrastructure of the host community.

\subsection{Environmental impacts}

Tourism development generates income that often makes it possible to protect and preserve the natural resources like oceans, lakes, natural parks and other scenic areas of beauty of the host communities, improvement in waste management and appearance of the sites and community as a whole, increasing environmental awareness and prevention of further ecological decline. Some of the negative environmental impacts of tourism are as follows: increase in water and energy consumption; increase in pollution (air, water, noise, etc.); destruction of flora and fauna, deforestation; increase in solid waste; disruption of wildlife behavior and feeding and breeding patterns; crowding and congestion; impact on aesthetic appeal of destination; and disturbing ecosystems.

\section{5 '3 Ss' tourism}

One of the most popular types of tourism is 3 Ss tourism which is usually associated with mass tourism [37]. In coastal areas, the three S's of sun, sea, and sand have attracted millions of tourists throughout the world. This type of tourism which is the main cause of developing too many buildings, too close to beaches, is associated with the emergence of a leisure-dominated pleasure periphery occupying a significant portion of the Mediterranean and Carribean basins, along with the parts of the South-Pacific, South-eastern Asia and Indian Ocean basin [26, p. 36]. At times the infrastructure has lagged behind development or has not been maintained, including sewerage, water and power facilities, roads and rubbish clearance [11, p. 249]. Because of failure in sustainable development of tourism industry, there is water, air, beach, and noise pollution. Mass tourism has been criticized for its destructive impact on local and traditional communities and cultures and on areas such as the coastline of Spain and the beaches of Thailand and Mexico. 3 Ss tourism has become symbolic of the negative economic, environmental and socio-cultural impacts. There has been a failure to conserve many of the world's coastal areas against the increasing numbers of tourists who are interested in 3 Ss tourism, the kind of tourism which although is more in harmony with the unsustainable paradigm, it is very popular and demanded throughout the world [11, p. 6]. Oceans are very important for climate stability, adequate food supply, healthy tourist industries and access to new sources of minerals and other resources for potential medical cures [24, p. 108]. According to Earle, the living ocean drives planetary chemistry, governs climate and weather, and otherwise provides the cornerstone of the life-support system for all creatures on our planet, from deep-sea starfish to desert sagebrush. If the sea is sick, we'll feel it. If it dies, we die [10]. Unfortunately, these critical resources for human life serve as dumps for the world's wastes both incidentally and intentionally. Incidentally, runoff from urban regions located near ocean shores goes into the ocean and creates pollution 
in coastal regions. Intentionally dumping of hazardous wastes, sewage discharge, and garbage from coastal cities into the seas has long been practiced under the mistaken notion that the vastness of the oceans would allow relatively small amounts of waste to dissipate and harmlessly disappear [24, p. 109]. Obviously the ocean is a complex ecosystem and there are complex interconnections and interrelatedness among its elements. When one element changes, others may be modified in turn. For example, when the number of tourists in a coastal area exceeds far beyond its carrying capacity, the run off from the seashore goes into the ocean, and disturbs the whole ecosystem.

\section{Few facts, lessons from experience}

- The Caspian Sea region in the North of Iran enjoys a competitive advantage in its natural attractions for tourism, consisting of extensive coastline, unparalleled environmental and cultural wealth, hospitality and generosity of its local people. Since sustainability does not receive the attention it deserves from neither parts of the society (public, private, and civil), its fragile eco-systems have been exposed to risk of coastal degradation. Due to an inadequate sewage disposal system, liquid and solid waste, air and water pollution, over-crowding far beyond the carrying capacity of the area, the quality of environment is severely threatened.

- The Gulf of Manner, located in the West Coast of Sri Lanka, contains 21 islands made up of coral and coral rubble and comprises a unique ecosystem within which rich biodiversity is found. The effects of pollution, especially from industries, coral mining, unsustainable fisheries management, overcropping of economically valuable seaweed species and sea cucumber species are causes for concern and urgent action if the biosphere reserve is to remain a haven for various rare and endemic species and the enormous variety of biodiversity [4, p. 155].

- A number of factors increasingly threaten the environmental quality of the Caribbean and hence the sustainability of the tourism industry. These include: poor sewage disposal; growing quantities of ship/boat-generated waste; beach erosion; destruction of reefs, water quality; over-fishing; destruction of wildlife habitat; over-crowding; carrying capacity limits; treatment of solid waste [27, p. 148].

- $\quad$ One of the most famous long-term tourism protests has been in Goa beach in India. With one five-star hotel consuming as much water as five local villages and one five-star tourist consuming 28 times more electricity per day than a local Goan, local discontent over resource-use is understandable [31, p. 3].

- Some of the urban-area beaches in New York and New Jersey have been closed to summer swimmers due to high fecal contamination of the waters or dangerous medical wastes on the shores [24, p.109].

These examples are merely part of the cascade of unexpected outcomes and unavoidable effects of mass tourism on the resources upon which it relied. 
Tourism authorities should be aware of these unexpected outcomes and guard against them in their tourism development strategies, and by overt management approaches try to regulate tourism behavior in coastal areas.

\section{Tourism impact assessment}

Tourism impact assessment is regarded as a key mechanism in achieving improvement in the quality of tourism industry in the host communities. There are a large number of assessment techniques for identification, collection and organization of data related to tourism impacts on host communities. Situation Analysis and Environmental Impact Assessment are two of the more common techniques which are described in this article. Followed by a brief description of these techniques, the author presents a framework for assessing tourism impacts in coastal environment.

\subsection{Situation analysis}

One of the most common tools for analysis of the situation is SWOT matrix. In this two-way matrix, SWOT stands for strengths, weaknesses, opportunities, and threats. The strengths and weaknesses come from the consideration of the internal position of the organization with opportunities and threats coming from a consideration of the external environment [5, p. 97]. This effective tool enables the decision-makers to consider the questions in relation to the environment and also the questions in respect to their own characteristics. SWOT matrix should be used to analyze every tourism development project in the host communities, exploring the various issues likely to influence the valuable natural asset, and if the project is well-suited to the area, then tourism authorities may be prepared to cope with its significant impacts on the coastal regions.

\subsection{Environmental impact assessment (EIA)}

EIA is the process of predicting and evaluating the impacts of specific developments or actions on the environment. The EIA process involves:

- Reviewing the existing state of the environment and the characteristics of the proposed development.

- $\quad$ Predicting the state of the future of the environment with and without the development.

- Considering the methods for reducing or eliminating any negative impacts.

- $\quad$ Producing the environmental impact statement for public consultation that discusses these points.

- $\quad$ Making a decision about whether the development should proceed in the proposed site, along with a list of relevant mitigation measures [35, p. 504]. 


\subsection{Tourism impact assessment in coastal areas (TIACA)}

TIACA is an assessment method that provides a specific list of environmental and other parameters which may be affected by tourism development projects. Some of the most important parameters that should be considered in tourism projects in coastal areas are listed in this framework. According to the nature of the project, the list can be made simple or descriptive, presenting more elaboration on the magnitude of impacts in the coastal zone. Since the environmental resources are the bottom line of the tourism attractions in coastal areas, the parameters are divided into two main categories: environmental parameters and other parameters: economic, social and cultural, political and etc., (Table 1). The basic concept of this technique is to provide community and tourism leaders with necessary information for decision-making about the tourism projects in coastal areas and changing the operation practices before negative impacts reach a critical level and degrade the fragile and vulnerable environment.

Table 1: $\quad$ Tourism impacts assessment in coastal environment.

\begin{tabular}{|c|c|c|c|c|c|c|}
\hline \multirow[t]{2}{*}{ Category of impact } & \multicolumn{3}{|c|}{ Construction phase } & \multicolumn{3}{|c|}{ Operation phase } \\
\hline & $\begin{array}{l}\text { No } \\
\text { impact } \\
\end{array}$ & $\begin{array}{l}\text { Few } \\
\text { impacts }\end{array}$ & $\begin{array}{l}\text { Serious } \\
\text { impacts }\end{array}$ & $\begin{array}{l}\text { No } \\
\text { impact }\end{array}$ & $\begin{array}{l}\text { Few } \\
\text { impacts }\end{array}$ & $\begin{array}{l}\text { Serious } \\
\text { impacts }\end{array}$ \\
\hline \multicolumn{7}{|l|}{$\begin{array}{l}\text { 1.Environmental } \\
\text { impacts }\end{array}$} \\
\hline \multicolumn{7}{|l|}{ Air quality } \\
\hline \multicolumn{7}{|l|}{ Water quality } \\
\hline \multicolumn{7}{|l|}{ Soil quality } \\
\hline \multicolumn{7}{|l|}{ Noise pollution } \\
\hline \multicolumn{7}{|l|}{ Sewage disposal } \\
\hline \multicolumn{7}{|l|}{ Flora \& fauna } \\
\hline \multicolumn{7}{|l|}{ Biodiversity } \\
\hline \multicolumn{7}{|l|}{ Waste } \\
\hline \multicolumn{7}{|l|}{ Land use } \\
\hline \multicolumn{7}{|l|}{ Scenery } \\
\hline \multicolumn{7}{|l|}{ Beach } \\
\hline \multirow{2}{*}{\multicolumn{7}{|c|}{ 2. Other impacts }} \\
\hline & & & & & & \\
\hline \multicolumn{7}{|l|}{ Local culture } \\
\hline \multicolumn{7}{|l|}{ Health } \\
\hline \multicolumn{7}{|l|}{ Economy } \\
\hline \multicolumn{7}{|l|}{ Infrastructure } \\
\hline \multicolumn{7}{|l|}{ Energy consumption } \\
\hline \multicolumn{7}{|l|}{ Workforce } \\
\hline \multicolumn{7}{|l|}{ Education } \\
\hline \multicolumn{7}{|l|}{ Population } \\
\hline \multicolumn{7}{|l|}{ Traffic } \\
\hline \multicolumn{7}{|l|}{ Crime } \\
\hline \multicolumn{7}{|l|}{ Housing } \\
\hline Security & & & & & & \\
\hline & & & & & & \\
\hline
\end{tabular}




\section{Conclusion}

Due to mass tourism, coastal areas are under increasing environmental stress and degradation. The causes include increasing pressure from energy consumption, green house gases, climate change, inadequate sewage treatment systems, run-off of soil and wastes to the seas, coastal erosion and silting due to unplanned constructions etc., which all lead to disturbing coastal ecosystems. Countries should implement effective programs to rehabilitate the damaged ecosystems and commit themselves to move towards sustainability of coastal zones

The following are some suggestions to minimize the negative impacts of tourism on the coastal environments which are part of mankind's heritage:

\subsection{Knowledge of complex systems}

A new world view in tourism system is necessary in order to achieve environmental conservation in coastal areas. This new paradigm should focus on the interrelatedness between human and nature and views them as integrated complex adaptive social-ecological entities. These systems are dynamic, changeable, largely unpredictable and only minimally explainable by linear cause and effect science [13, p. 113]. The evolution of complex systems is the outward expression of a process of self-organization driven by circular flows of energy, materials and information that originate largely from the sun and are organized as feedback loops [13, p. 114]. Some feedback loops are reinforcing, such as addition of hotels and facilities owing to increased tourism demand (positive feedback), while some are reverse flows, acting as regulators (negative feedback) in the case of policies intend to limit or better control further development, such as de-marketing (spatial and temporal zoning of use, restrictions of use intensity or of activities). The components of integrated complex adaptive systems are linked in a network of connections of varying intensities. Due to this interrelations, a change or disturbance in one part of the system is likely to have repercussions throughout the system [23]. The knowledge of these complex systems is necessary to reinforcing conservation policies in coastal regions.

\subsection{Increasing local people awareness}

Raising the awareness of local residents in coastal areas about the severe impacts of uncontrolled tourism development on deteriorating the fragile environment is very important for conservation of resources in coastal regions. An entirely new approach to conservation is required to protect the coastal areas, using the local inhabitants capable of managing the region through involvement in planning, decision-making and implementing all the tourism development projects in coastal regions. A decentralized bottom-up approach to coast conservation must be adopted and local people should be actively involved in the process. The prerequisite of this participation is raising the local inhabitant's awareness about the threats to their environment. According to the findings of a research which was conducted to examine the perception of environmental impacts of tourism 
between residents and managers within a protected area in Annapurna Conservation Area Project, Nepal, local residents were consistently more likely to perceive fewer negative and greater positive impacts of tourism on the environment. This is due to inadequate local residents' environmental knowledge to realize the impacts of tourism [30, p.58]. Although the environmental impacts of tourism development might have been justified by employment and individual economic gains $[29,30,36]$, but these benefits can only continue if the quality of the environment is not threatened. Local people should learn to use their assets but not to use them up. It must be a strategic objective to live on the interest from tourism but not to consume the capital [27, p. 267]. This objective can only be met and the economic gains can only be continued if the asset is used properly, otherwise the capital would vanish. Local people must be trained about environmental protection and sustainable forms of tourism.

\subsection{Collaboration of three sectors}

For the tourism industry to be sustainable, it is cooperation that matters. Tourism operations must not jeopardize essential ecological processes; it should respect the socio-cultural authenticity of the host community, and provide fair economic returns to all stakeholders [1, p.2]. These goals can only be attained if the numerous organizations in public, private, and social sectors, do not work on their different agendas with narrow interests. There should be a basic commitment to sustainability of environment in general and coastal areas in particular, in all three sectors. They must cooperate towards attainment of the common goal within a comprehensive tourism system. This system includes significant social, economic, geological and ecological components, along with the processes and functions that are essential for sustainability [12].

\subsection{Green productivity in tourism industry}

Environmental resources must be valued in the same way that other assets are valued. In this case, people must learn to use the natural resources more efficiently and to conserve them for the next generations. Productivity is the relationship between what is produced and the resources used to produce it. Productivity can be improved by doing more with the same resources through effective and efficient transformation of resources into desired output. To enhance productivity, output may be increased by advanced production technology, and/or input may be decreased by the waste management. The central element of the green productivity is the examination and re-evaluation of production process to highlight ways to improve productivity, while reducing their environmental impact [16, p.594]. Green productivity should be the mainstream of tourism development strategy in coastal areas and its application may be assessed by green productivity index (GPI), which is defined as the ratio of productivity of the system to its environmental impact [21, p.673]. Using this index is very important in environmental resources accounting. 


\subsection{Shift in tourism researches}

Tourism impacts on coastal areas should not be assessed only in terms of visual damage to the seashores in a short period of time. The impacts of tourism on the environment will only become known over a longer period of time and there are insufficient data on ecological systems to evaluate their sustainability [11, p. 247]. Ecosystems may not show signs of stress until suddenly a threshold is crossed when they collapsed and flip to another state [15]. Decision-making has become increasingly data-driven, but the environmental domain has lagged in this regard, as it is a fundamentally multi-dimensional concept such as natural resource depletion, pollution, and ecosystem destruction [16, p. 606]. Researchers must regard the long term and indirect changes in the coastal ecosystem behaviour and assess the disturbance and stress impacts on the region in a longer period of time by longitudinal methodologies. These studies should employ multidisciplinary and trans-disciplinary approaches if they are to include all different impacts of tourism development on the coastal areas. These kinds of research will provide valuable information for developing sound strategies that will optimize impacts of tourism in coastal environments.

\section{References}

[1] Black, R. and A. Crabtree (2007) Quality assurance and certification in ecotourism, CAB International, Oxfordshire, UK.

[2] Budowski, G. (1976), 'Tourism and environmental conservation: conflict, coexistence, or symbioses, Environmental Conservation, 3(1): 27-310.

[3] Butler, R. (1980) 'The concept of a tourism area cycle of evolution', Canadian Geographer, Vol. 24.

[4] Chawala, Romela (2006) Ecotourism planning and management, Sonali Publications, New Delhi, India.

[5] Clark, Alan and Wei Chen (2007) International hospitality management, concepts and cases, Elsevier, Oxford, UK.

[6] Cohen, E. (1978) 'The impact of tourism on the physical environment', Annals of Tourism Research, 5(2): 215-237.

[7] Cooper, Chris and Michael Hall (2005) Oceania, a tourism handbook, Channel View Publications, Clevedon, England.

[8] Craig-Smith, Stephen, J. (2005) 'Global warming and tourism in Oceania', in Cooper and Hall, Opcit.

[9] Edgel, David, L. (1990) International tourism policy, Publisher: Van Nostad Reinhard, USA.

[10] Earle, Sylvia, A. (1995) Sea Change, New York: Fawcett Columbia, USA.

[11] Elliot, James (1997) Tourism politics and public sector management, Routledge, London, UK.

[12] Farrell, B.H. and Twining-Ward, L. (2004) 'Re-conceptualizing tourism', Annals of Tourism Research, 31,(2), 274-95. 
[13] Farrell, B.H. and Twining-Ward, L. (2005) 'Seven steps towards sustainability: Tourism in the context of new knowledge', Journal of Sustainable Tourism, Vol. 13, No2, 109-122.

[14] Fennel, David, A. (1999) Ecotourism, an introduction, second eddition, Routledge, London and New York.

[15] Gunderson, L. H, et al. (1995) Barriers and bridges to renewal of ecosystems and institutions, Columbia University Press, New York.

[16] Gandhi, N.M. et al. (2006) 'Green productivity indexing, a practical step towards integrating environmental protection into corporate performance', International Journal of Productivity and Performance Management, Vol. 55, Number 7, 594-604.

[17] Harsell, Jan Van (1994) Tourism an exploration, Third edition, PrenticeHall International, Inc.

[18] Higham, James (2007) Critical issues in ecotourism, understanding a complex tourism phenomenon, Elsevier, New York.

[19] Holloway, J.C. (1994) 'The business of tourism', 4 ${ }^{\text {th }}$ edition, Pitman, London, UK.

[20] Hunter, Colin and Howard Green (1996) Tourism and the environment, Routledge, London and New York.

[21] Hur, T. et al. 'Measurement of green productivity and its improvement', Journal of Cleaner Production, Vol. 12 No. 7. PP 673-83.

[22] Jenkins, J. M. (1995) Tourism and public policy, Routledge, New York, USA.

[23] Jervis, R (1997) System effects: Complexity in political and social life, Princeton University Press, USA.

[24] Kelleher A. and Klein, L (1999) Global perspectives, a handbook for understanding global issues, Prentice Hall, New Jersey,USA.

[25] Krippendorf, J. (1977) 'Les devoreurs des paysages, Lausanne: 24 Heures, In Fennel, Opcit.

[26] Lawton, L and D. Weaver (2000) 'Nature based tourism and ecotourism' in: Tourism in $21^{\text {st }}$ century, lesson from experience, Edited by Bill Faulker, Continuum, London.

[27] Lockwood, A and S. Medlik (2003) Tourism and hospitality in the $21^{\text {st }}$ century, Elsevier Ltd., Oxford, U.K.

[28] Mader, U. (1999) 'Tourism and the environment', Annals of Tourism Research, Vol.15, No.2.

[29] Mehta J. and S. Kellert (1998) 'Local attitudes toward community-based conservation policy and programs in Nepal, a case study of the MakaluBarun Conservation Area', Environmental Conservation, 25(4): 320-33.

[30] Nyaupane, Gyan and Brijesh Thapa (2006) 'Perceptions of environmental impacts of tourism: A case study at ACAP, Nepal', International Journal of Sustainable Development and World Ecology, 13, 1.

[31] Narasaiah, M.L.(2007) Tourism and development, Discovery Publishing House,India.

[32] Page, Stephen (1994) Transport for tourism, Routledge, London and New York. 
[33] Pearce, D. G. (1985) 'Tourism and environmental research: a review', International Studies, 25: 247-255.

[34] Ryan, Chris (1995) Recreational tourism, a social science perspective, Routledge, New York, USA.

[35] Synergy (2000) Tourism Certification: An analysis of Green Globe 21 and other tourism certification programs, WWF-UK, London, UK.

[36] Walpole M. and H. Goodwin (2001), 'Local attitudes towards conservation and Tourism around Komodo National Park, Indonesia, Environmental Conservation, 28 (2): 160-6.

[37] Weaver, D. (2001) Ecotourism, John Wiley and Sons: Australia, Milton, Queensland. 